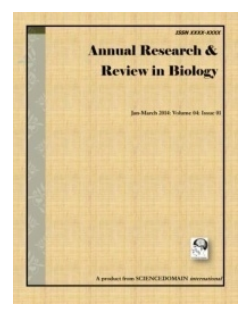

\title{
Persistent and Transient Inhibition of Seed Germination by Fractions of Methanol-Water Extract of Wheat Straw
}

\author{
L. S. Dias ${ }^{1^{*}}$ \\ ${ }^{1}$ Department of Biology, School of Sciences and Technology, University of Évora, Ap. 94, \\ 7002-554 Évora, Portugal.
}

Author's contribution

This whole work was carried out by author LSD.

Original Research Article

Received $13^{\text {th }}$ June 2014

Accepted $8^{\text {th }}$ July 2014

Published 19 ${ }^{\text {th }}$ July 2014

\section{ABSTRACT}

The objectives of this work were to investigate the effects of wheat straw constituents on total seed germination and on time needed for seed germination to start and to assess the usefulness of evaluating the recovery of germination to help guide the screening for a sequential search of bioactive natural phytochemicals. Dose-response bioassays of lettuce seed germination to increasing concentrations of six fractions of methanol-water extract were conducted and whenever inhibition of germination exceeded $90 \%$ non-germinated seeds were transferred to distilled water and recovery of germination investigated. Only the fractions essentially composed by neutral polar compounds and by acids failed to inhibit total germination. Fractions composed by strong acids, basic compounds and fatty acids plus steroids completely inhibited total germination at $5 \mathrm{mg} \mathrm{mL}^{-1}$, the former also inhibiting germination by more than $90 \%$ at $1 \mathrm{mg} \mathrm{mL}^{-1}$. In these three fractions the concentration necessary for $100 \%$ inhibition was estimated to range between $4.1 \mathrm{mg} \mathrm{mL}^{-1}$ and $4.4 \mathrm{mg} \mathrm{mL}^{-1}$. Time needed for germination to start was always significantly increased even by fractions that failed to affect total germination. Basic compounds were the most effective in delaying the start of germination increasing it more than 4-fold at $2 \mathrm{mg} \mathrm{mL}^{-1}$ from 1.0 to 4.3 days. When non-germinated seeds were transferred to distilled water persistence of complete inhibition was only found with strong acids, almost full persistence with basic compounds. Thus the consideration of recovery of germination makes possible a more informed choice of the fraction to select for further bioassay guided search for phytochemical with herbicide activity. The fraction is the one composed by strong acids, 
mainly phenolic acids, all of them identified, provided that persistent seed inhibition is desired and long term weed control through depletion of weed seed banks in soil is aimed.

Keywords: Allelopathy; fractions; germination; persistent effects; transient effects; wheat straw.

\section{INTRODUCTION}

A high number of natural compounds from living or dead plant material are active on a large number of plant processes at various levels of organization $[1,2]$. Such chemicals may have a high potential to provide alternative and more natural ways of controlling and managing weed populations [3] and in the framework of allelopathic investigation the search for chemicals with herbicide activity has grown over the years. Microbes [4], fungi [5,6] and a variety of higher plants [7-9] have been investigated with that purpose.

Wheat and especially wheat straw has been intensively searched [10-12] generally by testing complete extracts. Water extracts of wheat straw have been found to be effective against a number of species sometimes with stimulatory activity [13] or more frequently inhibiting seed germination and seedling growth [13-15].

However bioassay-guided fractionation and structure optimization of selected compounds has been proposed and has received increasing attention [16-18]. In parallel, research has also been carried to establish more adequate and more rigorous bioassays and methods to investigate seed germination responses to allelopathins, namely in relation to the dependency of functional availability of phytochemicals on seed density $[19,20]$, biologically meaningful parameterization of seed germination or growth over time [21,22] and the relevance of seed morphology including seed volume on seeds responses to allelopathic compounds [23].

Finding natural compounds that completely or almost completely inhibit germination of potential competitors like weed species has long been a goal of allelopathic research. However, if inhibition of germination is transient and disappears after the disappearance of the compounds responsible for it, the result will be the maintenance of a viable seed bank in soil requiring control of seed germination to be done year after year. Conversely, persistence of effects on germination after the inhibitory agents disappear would provide a much more efficient weed control because of the resulting progressive depletion of weeds seed banks.

Therefore this study was conducted 1) To investigate the effects of a series of concentrations of six different fractions of the methanol-water extract of wheat straw on total seed germination and on time needed for seed germination to start and 2) To assess the usefulness of evaluating the recovery of germination to help guide the screening for sequential search of bioactive natural phytochemicals.

\section{MATERIALS AND METHODS}

\subsection{Wheat Straw Extraction and Fractioning}

Extraction and fractioning of wheat straw followed the procedures described elsewhere [24]. Dried baled wheat straw was finely chopped, washed with water, extracted with $\mathrm{MeOH}: \mathrm{H}_{2}$, 
the liquid filtered and dried. The dry residue was re-dissolved in water, mixed with $\mathrm{KHCO}_{3}$ to $\mathrm{pH} 8$ and extracted with diethyl ether. The aqueous layer was acidified to $\mathrm{pH} 1$ with $\mathrm{HCl}$ and extracted with diethyl ether. The resulting aqueous layer will be referred to as fraction $A$, and the organic layer as fraction $B$. The ether fraction was extracted with $\mathrm{KHCO}_{3}$, the resulting aqueous layer was acidified to $\mathrm{pH} 1$ with $\mathrm{HCl}$, extracted with diethyl ether, washed with water, yielding the fraction $C$, and the ethereal layer was re-extracted with $\mathrm{NaOH}$. The resulting aqueous layer was acidified to $\mathrm{pH} 1$ with $\mathrm{HCl}$, extracted with diethyl ether and washed with water (fraction $D$ ) and the organic layer was extracted again with $\mathrm{HCl}$. The resulting aqueous layer was made alkaline with $\mathrm{NaOH}$, the solvent evaporated and dried over $\mathrm{P}_{2} \mathrm{O}_{5}$ giving the fraction $E$. Fraction $F$ was obtained by washing the organic layer with water and evaporating the solvent.

\subsection{Germination Bioassays of Fractions}

Because of the small amounts of dried fractions (minimum of $59.3 \mathrm{mg}$ in fraction $E$ ) lettuce (Lactuca sativa L.) was selected as target species because of the small size of its seeds and its adequacy for experiments of this kind [25]. An exploratory experiment in which four lettuce cultivars were compared showed a higher performance of cv. 'Iceberg' (data not shown) prompting for its use to evaluate the effects of fractions on seed germination. Solutions $5,2,1$ and $0.5 \mathrm{mg} \cdot \mathrm{mL}^{-1}$ were prepared by dilution with distilled water of a stock solution of dried aliquots of fractions $A-F$ made of $1 \mathrm{~mL}$ of methanol plus distilled water and bioassayed on germination of lettuce seeds cv. 'Iceberg'. In each treatment four $60-\mathrm{mm}$ glass Petri dishes were fitted with Whatman ${ }^{\circledR}$ No. 1 paper, sown with 10 seeds of lettuce, and wetted with $1 \mathrm{~mL}$ of the appropriate solution. Controls were prepared likewise with $1 \mathrm{~mL}$ of methanol and distilled water at the same rates as in fraction treatments. Seeds were incubated under constant $20^{\circ} \mathrm{C}$ and $8 \mathrm{~h}$ photoperiod provided by seven fluorescent tubes (Philips TLD 18W/84). Seeds were considered germinated if the radicle was at least as long as seed length. Germinated seeds were regularly counted and discarded during 8 days. Non germinated seeds of treatments with inhibition of total germination larger than $90 \%$ were washed with distilled water and transferred to newly prepared glass Petri dishes wetted with $1 \mathrm{~mL}$ of distilled water, incubated as described above and germinated seeds were regularly counted and discarded during 8 more days to evaluate the persistence of inhibitory effects.

\subsection{Statistical Analyses}

Total germination $\left(\mathrm{G}_{\mathrm{T}}\right)$ before seed transferal to distilled water to evaluate recovery of germination was investigated by exact or approximate two-tailed Student's $t$ tests after checking for homocedasticity using the two-tailed $F$ distribution.

Time-course of germination was modelled separately for each treatment using the threeterm Weibull function [26], a highly flexible and useful equation to describe germination in phytotoxic and allelopathic studies [22], and can be expressed as:

$$
\mathrm{G}=1-\exp -\left\{[(\mathrm{T}-I) / k]^{c}\right\}
$$

Where $\mathrm{G}$ is the cumulative germination at time $T$ as proportion of total germination $\mathrm{G}_{\mathrm{T}}, \mathrm{I}$ is a location parameter that for all practical purposes estimates the time at which the first seed germinates (lag of germination), $k$ is a scale parameter with $l+k$ estimating the time at which approximately $63 \%$ of cumulative germination occurred and $c$ is a shape parameter. 
To investigate the relationship between total germination $\left(\mathrm{G}_{T}\right)$ and concentration $\mathrm{G}_{T}$ was normed so that the control was $100 \%$. An exploratory visual examination of the responses of germination to the concentration of fractions strongly suggested that a sigmoidal model expressed as a modified Weibull equation (Equation 2) could adequately describe the relationship between total germination and fractions concentration and that a polynomial model could adequately describe the relationship between the lag of germination $(I)$ and fractions concentration:

$$
\mathrm{G}_{\mathrm{C}}=\exp -(\mathrm{C} / k)^{c}
$$

Where $G_{C}$ is the total germination in percentage of control at concentration $C, k$ is a scale parameter estimating the concentration at which $\mathrm{G}_{\mathrm{C}}$ is approximately $37 \%$ and $c$ is a shape parameter.

Equations (1) and (2) were fitted by least squares nonlinear regression with replication with the Marquardt method [27]. Lack of fit was tested for $P=.05$, parameters and estimates were checked against original data, and coefficients of determination $\left(R^{2}\right)$ are expressed as proportion of the maximum $R^{2}$ possible [28]. Polynomials were fitted by least squares stepwise linear regression without replication and an experiment-wise error rate for regression coefficients of .05 estimated by Dunn-Šidak method [29]. Coefficients of determination are presented after being adjusted to degrees of freedom $\left(R_{\text {adj }}^{2}\right)$.

Recovery of germination was calculated in percentage as $100\left(G_{R} / G_{F}\right)$ with $G_{R}$ being the number of seeds that germinated after being transferred from treatments to distilled water and $G_{F}$ the number of non-germinated seeds in treatments before that transferal to distilled water [30]. Total germination and recovery of germination after seed transferal to distilled water was investigated by exact or approximate one-tailed Student's $t$ tests after checking for homocedasticity using the two-tailed $F$ distribution.

A significance level of $P=.05$ was used throughout and data is presented as mean \pm standard error. Linear and nonlinear regression analyses and ANOVAs were done with Statgraphics 4.2 (STSC, Inc., Rockville, MD, USA), all other statistics with Excel ${ }^{\circledR} 2010$ (Microsoft Corporation).

\section{RESULTS AND DISCUSSION}

\subsection{Total Germination}

Data of total germination before transferal of non-germinated seeds to distilled water are summarized in Table 1. Total germination $\left(\mathrm{G}_{\mathrm{T}}\right)$ was $97.5 \pm 1.2 \%$ in controls and significant inhibition of $\mathrm{G}_{\mathrm{T}}$ was found in all fractions except when seeds were treated with fractions $A$ or $C$ which are essentially composed by neutral polar compounds like sugars and amino acids or by acids respectively.

Conversely fraction $B$ significantly inhibited seed germination at all concentrations tested while the remaining fractions (fractions $D-F$ ) significantly inhibited seed germination but only at the highest concentration tested. In addition complete inhibition of $\mathrm{G}_{\mathrm{T}}$ was found in seeds treated with fractions $B, E$ and $F$ but only at $5 \mathrm{mg} \mathrm{mL}^{-1}$. 
Table 1. Total germination of lettuce seeds treated with fractions of methanol-water extract of wheat straw

\begin{tabular}{|c|c|c|c|c|c|c|}
\hline \multirow{2}{*}{$\begin{array}{l}\text { Concentration } \\
\left(\mathrm{mg} \cdot \mathrm{mL}^{-1}\right)\end{array}$} & \multicolumn{6}{|c|}{ Fraction } \\
\hline & A & B & C & D & E & $F$ \\
\hline 0 & $97.5 \pm 1.2$ & $97.5 \pm 1.2$ & $97.5 \pm 1.2$ & $97.5 \pm 1.2$ & $97.5 \pm 1.2$ & $97.5 \pm 1.2$ \\
\hline 0.5 & $97.5 \pm 2.5$ & $85.0 \pm 6.5$ & $100 \pm 0$ & $100 \pm 0$ & $97.5 \pm 2.5$ & $97.7 \pm 2.3$ \\
\hline 1 & $\begin{array}{l}(\approx 1) \\
100 \pm 0\end{array}$ & $\begin{array}{l}\left(.35 \times 10^{-2}\right) \\
5.0 \pm 2.9\end{array}$ & $\begin{array}{l}(.38) \\
100 \pm 0\end{array}$ & $\begin{array}{l}(.38) \\
97.5 \pm 2.5\end{array}$ & $\begin{array}{l}(\approx 1) \\
90.0 \pm 7.1\end{array}$ & $\begin{array}{l}(.94) \\
100 \pm 0\end{array}$ \\
\hline 2 & $\begin{array}{l}(.38) \\
92.5 \pm 4.8\end{array}$ & $\begin{array}{l}\left(.17 \times 10^{-18}\right) \\
2.5 \pm 2.5\end{array}$ & $\begin{array}{l}(.38) \\
97.5 \pm 2.5\end{array}$ & $\begin{array}{l}(\approx 1) \\
97.5 \pm 2.5\end{array}$ & $\begin{array}{l}(.07) \\
42.5 \pm 7.5\end{array}$ & $\begin{array}{l}(.38) \\
92.5 \pm 2.5\end{array}$ \\
\hline 5 & $\begin{array}{l}(.16) \\
92.5 \pm 2.5\end{array}$ & $\begin{array}{l}\left(.64 \times 10^{-19}\right) \\
0 \pm 0\end{array}$ & $\begin{array}{l}(\approx 1) \\
65.0 \pm 10.4\end{array}$ & $\begin{array}{l}(\approx 1) \\
25.0 \pm 5.0\end{array}$ & $\begin{array}{l}(.05) \\
0 \pm 0\end{array}$ & $\begin{array}{l}(.11) \\
0 \pm 0\end{array}$ \\
\hline & $(.11)$ & $\left(.98 \times 10^{-20}\right)$ & $(.05)$ & $\left(.48 \times 10^{-15}\right)$ & $\left(.20 \times 10^{-24}\right)$ & $\left(.98 \times 10^{-20}\right)$ \\
\hline
\end{tabular}

Values are means \pm standard errors (in percentage). Between brackets are significance levels $(P)$ of exact or approximate two-tailed Student's t comparisons with control. Sample size of controls $n=20$, otherwise $n=4$

Equation 2 could always be fitted to the relationship between total germination normed so that control is $100 \%$ and concentration except for bioassays involving fraction $A$ (Fig. 1). The coefficient of determination $R^{2}$ of equations ranged between 0.940 (fraction $B$ ) and more than 0.999 (fraction $E$ ) with a mean value ( \pm standard error) of $0.985 \pm 0.011$. Lack of fit was never significant $(P \geq .57)$ except for fraction $B\left(F_{2,31}=51.41, P=.14 \times 10^{-9}\right)$.

According to the response of lettuce germination, fractions $B, E$ and $F$ are highly promising sources of compounds able to completely inhibit germination at concentrations lesser than 5 $\mathrm{mg} \mathrm{mL}^{-1}$. In the re-parameterized Weibull equation (Equation 2) the scale parameter $k$ estimates the concentration at which total germination is approximately $37 \%$ which equates to the effective dose to reduce total germination by $63 \%\left(\mathrm{IC}_{63}\right)$. However, despite that $\mathrm{IC}_{63}$ or even the more common and less stringent $I_{50}[18,31]$ might be a good result to temporarily reduce the density of weeds and thus their competition with crop species, it is hardly a desirable target if a more permanent control is desired because it does not prevent the new production of seeds and thus the partial or complete replenishment of weed seed banks.

Therefore $\mathrm{IC}_{100}$ was deduced from fitted equations and concentrations for complete inhibition of germination of seeds by fractions were estimated by extrapolation to be $8.7 \mathrm{mg} \mathrm{mL}^{-1}$ in fraction $C$ and $5.9 \mathrm{mg} \mathrm{mL}^{-1}$ in fraction $D$, and by interpolation to be $4.4 \mathrm{mg} \mathrm{mL}^{-1}$ in fraction $E$, slightly less $\left(4.3 \mathrm{mg} \mathrm{mL}^{-1}\right)$ in fraction $F$ and $4.1 \mathrm{mg} \mathrm{mL}^{-1}$ in fraction $B$. Thus $\mathrm{IC}_{100}$ values for fractions $B, E$ and $F$ lie within a very narrow range of concentrations. All considered, inhibition of total germination and $I C_{100}$ fraction $B$ emerges as the most promising source for bioherbicides, followed by fraction $E$ while fraction $F$ ranks third.

Fraction $B$ is composed by strong acids including phenolic acids, fraction $E$ by basic compounds and fraction $F$ by neutral compounds. According to published work [32] fraction $B$ was in all likelihood essentially composed by phenolic acids which were very likely to include benzoic acid, trans-p-coumaric acid, cis- and trans-ferulic acids, fumaric acid, $p$ hydroxibenzoic acid, protocatechuic acid and vanillic acid. Similarly fraction $F$ was in all likelihood composed by fatty acid methyl esters and steroids, which might include azelate, palmitate, oleate, linoleate, campesterol, cholesterol, ergosterol and several ergosterol- 
derivatives, spinasterol and also a number of new or unusual ketosteroids [32,33]. So far no compounds have been identified in fraction $E$.
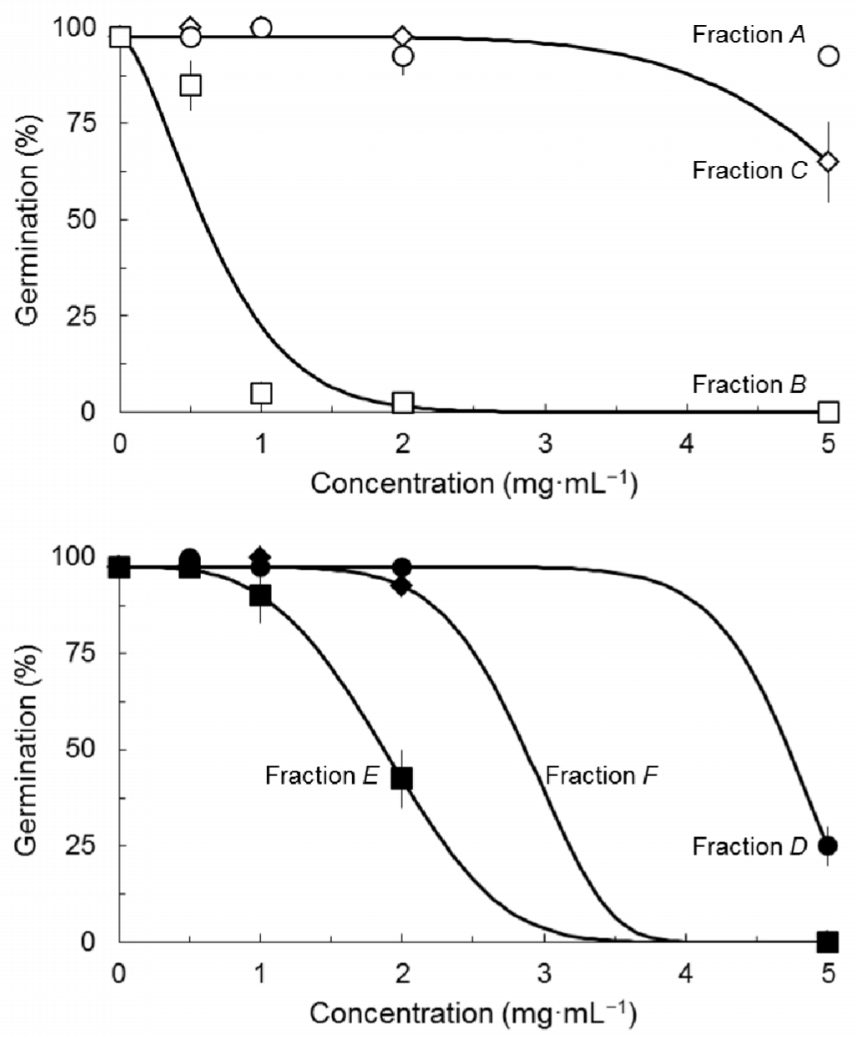

Fig. 1. Expected (mean \pm standard error) and observed effects of fractions of methanol-water extract of wheat straw on total germination of lettuce in percentage of control

Values for $k$ and $c$ in Equation 2 are: 0.773 and 1.499 (fraction B); 5.7996 and 6.106 (fraction C); 4.880, 12.643 (fraction D); 2.112 and 3.405 (fraction E); 3.041 and 7.046 (fraction F)

\subsection{Time-course of Germination}

Germination over time could almost always be fitted by the three-term Weibull equation (Equation 1) except for concentrations 1 and $2 \mathrm{mg} \mathrm{mL}^{-1}$ of fraction $B$ in which $\mathrm{G}_{\mathrm{T}}$ was too low and naturally for concentration $5 \mathrm{mg} \mathrm{mL}^{-1}$ of fractions $B, E$ and $F$ (Table 1). $R^{2}$ of Weibull equations ranged between 0.598 and 1 with a mean value ( \pm standard error) of $0.958 \pm 0.002$. Lack of fit was never significant $(P \geq .17)$. Therefore the relationship between the lag of germination and concentration was investigated in all fractions except in fraction $B$.

Polynomials could always be fitted and $R_{\text {adj }}^{2}$ ranged between 0.879 (fraction $A$ ) and 0.983 (fraction $D$ ) with a mean value ( \pm standard error) of $0.939 \pm 0.020$. Significance levels of individual coefficients and models were always less than .01. Fractions $A, C$ and $D$ were fitted by straight line equations while fractions $E$ and $F$ required exponential forms (Fig. 2). 

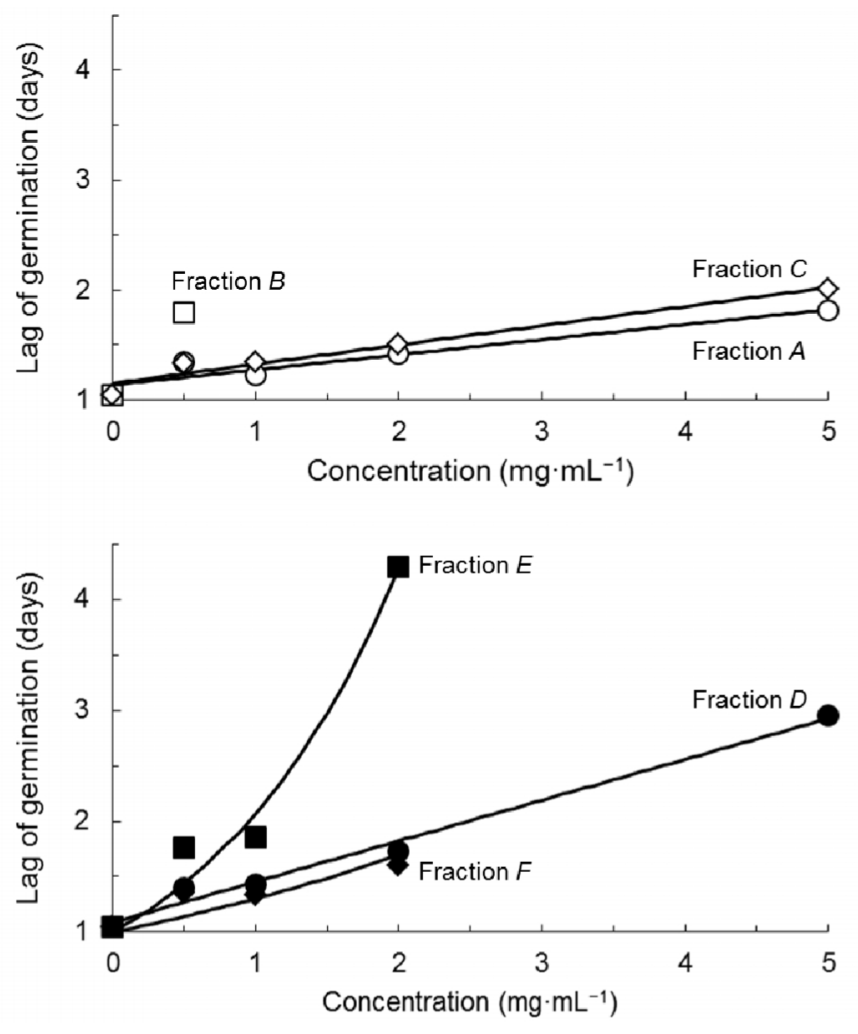

Fig. 2. Expected and observed effects of fractions of methanol-water extract of wheat straw on lag of germination of lettuce seeds

Equations for fractions $A, C$ and $D$ are of the type $Y=a+b X$ and values for $a$ and $b$ are: 1.137 and 0.137 (fraction $A$ ); 1.150 and 0.175 (fraction $C$ ); 1.087 and 0.368 (fraction $D$ ). Equations for fractions $E$ and $F$ are of the type $Y=\exp (\mathrm{aX})$ and values for a are: 0.727 (fraction $E$ ); 0.264 (fraction $F$ )

Lag of germination $(I)$ increased with concentration in all fractions meaning that regardless of the sensitivity of total germination $\mathrm{G}_{\mathrm{T}}$ to fractions and concentrations, the time needed for the first seed to germinate increased always with concentration. This is especially noticeable in fractions $A$ and $C$ which failed to affect $\mathrm{G}_{\mathrm{T}}$ (Table 1) but at $5 \mathrm{mg} \mathrm{mL}^{-1}$ increased / two-fold from 1.0 to 1.8 days or 2.0 days respectively.

In relation to / fraction $E$ was clearly the most effective significantly increasing it more than 4fold at $2 \mathrm{mg} \mathrm{mL}-1$ from 1.0 to 4.3 days with some tradeoff between inhibition and delay of germination. Again fraction $E$ fares better than fraction $F$.

\subsection{Recovery of Germination}

Five treatments resulted in more than $90 \%$ inhibition of $\mathrm{G}_{\mathrm{T}}$ and were investigated for the persistence of inhibitory effects. Cumulative results after transferring non-germinated seeds to distilled water are shown in Table 2.

Except fraction $B$ at $1 \mathrm{mg} \mathrm{mL}^{-1}$ in which complete recovery was observed, all other treatments inhibited lettuce germination at various rates after seeds were transferred to distilled water. However only seeds treated by fraction $B$ at $5 \mathrm{mg} \mathrm{mL}^{-1}$ were permanently 
inhibited after seeds were transferred to distilled water. Partial or almost full recovery was observed in the remaining treatments with fraction $E$ at $5 \mathrm{mg} \mathrm{mL}^{-1}$ closely resembling fraction $B$ at the same concentration.

In addition, recovery data of fraction $B$ strongly suggests that persistence of inhibitory effects might be concentration-dependent. Thus strong acids and phenolic acids that constitute this fraction may be able to permanently inhibit seed germination at concentrations between 2 and $5 \mathrm{mg} \mathrm{mL}^{-1}$ but further research is needed to ascertain whether or not, and how, such concentration-dependency could be used to allow a broader range of options for concentrations aimed at specified levels of permanent inhibition of seed germination.

Table 2. Total germination and recovery of non-germinated lettuce seeds treated with fractions of methanol-water extract of wheat straw after transferal to distilled water

\begin{tabular}{|c|c|c|c|}
\hline \multirow[t]{2}{*}{ Fraction } & Concentration & Germination & Recovery \\
\hline & $\left(\mathrm{mg} \cdot \mathrm{mL}^{-1}\right)$ & (\%) & (\%) \\
\hline Control & 0 & $97.5 \pm 1.2$ & $0 \pm 0$ \\
\hline$B$ & 1 & $94.7 \pm 3.1$ & $94.4 \pm 3.3$ \\
\hline$B$ & 2 & $\begin{array}{l}(.19) \\
62.2 \pm 9.8 \\
(.02)\end{array}$ & $\begin{array}{l}\left(.45 \times 10^{-4}\right) \\
60.7 \pm 10.8 \\
(.01)\end{array}$ \\
\hline$B$ & 5 & $\begin{array}{l}0 \pm 0 \\
(\approx 0)\end{array}$ & $\begin{array}{l}0 \pm 0 \\
(\approx 1)\end{array}$ \\
\hline$E$ & 5 & $\begin{array}{l}7.5 \pm 4.8 \\
(\approx 0)\end{array}$ & $\begin{array}{l}7.5 \pm 4.8 \\
(.11)\end{array}$ \\
\hline$F$ & 5 & $\begin{array}{l}67.5 \pm 10.3 \\
(.03)\end{array}$ & $\begin{array}{l}67.5 \pm 10.3 \\
\left(.36 \times 10^{-2}\right)\end{array}$ \\
\hline
\end{tabular}

Results of recovery of germination agree with and strengthen the choice of fraction $B$ for further studies aimed at finding highly effective natural compounds against germination of weed seeds. The fact that fraction $B$ is essentially composed by phenolic acids adds to the interest of its choice.

According to our data permanent inhibition of germination by fraction $B$ should occur at concentrations between $4.1 \mathrm{mg} \mathrm{mL}^{-1}$ (estimated $\mathrm{IC}_{100}$ ) and $5 \mathrm{mg} \mathrm{mL}^{-1}$. Because fraction $B$ is a mixture of compounds this means that each of the twenty compounds already identified in it are present in lower or much lower concentrations. Fraction $B$ is a mixture mostly composed of phenolic acids which essentially have the same sites of activity thus implying that their combined action is antagonistic or at most, additive [34]. Implications are that a search for the individual compounds responsible for the effects of fraction $B$ might result in finding phenolic acids permanently inhibitory of seed germination at very low dosages.

Also phenolic acids are known to degrade rapidly $[35,36]$ which means that in the case of its use as weedicide there is a good chance that after provoking permanent inhibition of weed seeds they will rapidly decompose and disappear from soil. 


\section{CONCLUSIONS}

Three of the six fractions of the methanol-water extract of wheat straw (fractions $B, E, F$ ) completely inhibited lettuce seed germination at $5 \mathrm{mg} \mathrm{mL}^{-1}$ and one of them, fraction $B$ essentially composed by phenolic acids also inhibited seed germination by more than $90 \%$ at $1 \mathrm{mg} \mathrm{mL}^{-1}$.

All fractions significantly increase the time necessary for the first seed to germinate with the most effective fraction (fraction $E$ ) being composed by basic compounds still unidentified.

The consideration of recovery of germination eliminates the appeal for fractions $E$ and $F$ as choices for further investigation because only fraction $B$ was able to completely and permanently inhibit germination.

\section{ACKNOWLEDGEMENTS}

Thanks are due to Elvira Gaspar (Chemistry Department, New University of Lisboa) for extraction and fractioning of wheat straw, to Gertrudes Mariano and Isabel Robalo (Biology Department, University of Évora) for technical assistance in bioassays, and to one anonymous referee for comments on the manuscript.

\section{COMPETING INTERESTS}

Author has declared that no competing interests exist.

\section{REFERENCES}

1. Rice EL. Allelopathy. 2nd ed. Orlando: Academic Press; 1984.

2. Rice EL. Overview of allelopathy. In: Narwal SS, Tauro P, Editors. Allelopathy in agriculture and forestry. Jodhpur: Scientific Publishers. 1994;1-18.

3. Bhadoria PBS. Allelopathy: A natural way towards weed management. Am J Exp Agric. 2011;1:7-20.

4. Hoagland RE. Microbial allelochemicals and pathogens as bioherbicidal agents. Weed Technol.2001;15:835-857.DOI:10.1614/0890037X(2001)015[0835:MAAPAB]2.0.CO;2.

5. Abbas HK, Duke SO, Merril Jr AH, Wang E, Shier WT. Phytotoxicity of australifungin, AAL-toxins and fumonisin $B_{1}$ to Lemna pausicostata. Phytochemistry. 1998;47:15091514.

6. Abbassy MA, Marzouk MA, Rabea El, Abd-Elnabi AD. Insecticidal and fungicidal activity of Ulvalactuca linnaeus (Chlorophyta) extracts and their fractions. Annu Res Rev Biol. 2014;4:2252-2262.

7. Dias LS, Pereira IP, Dias AS. Evaluation of Mediterranean-type vegetation for weedicide activity. Allelopathy J. 1995;2:197-203.

8. Czarnota MA, Paul RN, Dayan FE, Nimbal Cl, Weston LA. Mode of action, localization of product, chemical nature, and activity of sorgoleone: A potent PSII inhibitor in Sorghum spp. root exudates. Weed Technol. 2001;15:813-825. DOI:10.1614/0890037X(2001)015[0813:MOALOP]2.0.CO;2.

9. Dias AS, Dias LS, Pereira IP. Activity of water extracts of Cistus ladanifer and Lavandula stoechas in soil on germination and early growth of wheat and Phalaris minor. Allelopathy J. 2004;14:59-64. 
10. Alsaadawi IS. Allelopathic influence of decomposing wheat residues in agroecosystems. J Crop Prod. 2001;4:185-196. DOI:10.1300/J144v04n02_05.

11. Wu H, Pratley J, Lemerle D, Haig T. Allelopathy in wheat (Triticum aestivum). Ann Appl Biol. 2001;139:1-9. DOI:10.1111/j.1744-7348.2001.tb00124.x.

12. Ma Y. Allelopathic studies of common wheat (Triticum aestivum L.). Weed Biol Manag. 2005;5:93-104. DOI:10.1111/j.1445-6664.2005.00164.x.

13. Dias LS. Allelopathic activity of decomposing straw of wheat and oat and associated soil on some crop species. Soil Tillage Res. 1991;21:113-120.

14. Nakano $\mathrm{H}$, Morita S, Shigemori H, Hasegawa K. Plant growth inhibitory compounds from aqueous leachate of wheat straw. Plant Growth Regul. 2006;48:215-219. DOI: 10.1007/s10725-006-0006-6.

15. Khaliq A, Matloob A, Aslam F, Mushtaq MN, Khan MB. Toxic action of aqueous wheat straw extract on horse purslane. Planta Daninha. 2012;30:269-178.

16. Rimando AM, Olofsdotter M, Dayan FE, Duke SO. Searching for rice allelochemicals: anexample of bioassay-guidedisolation. Agron J. 2001;93:16-20. DOI: 10.2134/agronj2001.93116x.

17. Macías FA, Molinillo JMG, Chinchilla D, Galindo JCG. Heliannanes - A structureactivity relationship (SAR) study. In: Macías FA, Galindo JCG, Molinillo JMG, Cutler HG, editors. Allelopathy: Chemistry and modes of action of allelochemicals, Boca Raton: CRC Press. 2004;103-124.

18. Araniti F, Lupini A, Mercati F, Statti GA, Abenavoli MR. Calamintha nepeta L. (Savi) as source of phytotoxic compounds: Bio-guided fractionation in identifying biological active molecules. Acta Physiol Plant. 2013;35:1979-1988. DOI:10.1007/s11738-0131236-7.

19. Weidenhamer JD, Morton TC, Romeo JT. Solution volume and seed number: Often overlooked factors in allelopathic bioassays. J Chem Ecol. 1987;13:1481-1491. DOI: 10.1007/BF01012292.

20. Sinkkonen A. Modelling the effect of autotoxicity on density-dependent phytotoxicity. J Theor Biol. 2007;244:218-227. DOI:10.1016/j.jtbi.2006.08.003.

21. Streibig JC. Kudsk P, Jensen JE. A general joint action model for herbicide mixtures. Pestic Sci. 1998;53:21-28. DOI:10.1002/(SICI)1096-9063(199805)53:1<21::AIDPS748>3.0.CO;2-L.

22. Dias LS. Describing phytotoxic effects on cumulative germination. J Chem Ecol. 2001;27:411-418. DOI:10.1023/A:1005644808956.

23. Pellisier F. Improved germination bioassays for allelopathy research. Acta Physiol Plant. 2013;35:23-30. DOI:10.1007/s11738-012-1044-5.

24. Gaspar EM, Neves HC. Chemical constituents in allelopathic straw of wheat (Triticum aestivum L.). Allelopathy J. 1995;2:79-87.

25. Macías FA, Castellano D, Molinillo JMG. Search for a standard phytotoxic bioassay for allelochemicals. Selection of a standard target species. J Agric Food Chem. 2000;48:2512-2521. DOI:10.1021/jf9903051.

26. Weibull W. A statistical distribution function of wide applicability. J Appl Mech. 1951;18:293-297.

27. Marquardt DW. An algorithm for least-squares estimation of nonlinear parameters. $J$ Soc Ind Appl Math. 1953;11:431-441.

28. Draper NR, Smith H. Applied regression analysis. 3rd ed. New York: John Wiley; 1998.

29. Ury HK. A comparison of four procedures for multiple comparisons among means (pairwise contrasts) for arbitrary sample sizes. Technometrics. 1976;18:89-97. DOI:10.1080/00401706.1976.10489405. 
30. Khan MA, Gul B. High salt tolerance in germinating dimorphic seeds of Arthrocnemum indicum. Int J Plant Sci. 1998;159:826-832.

31. Dayan FE, Romagni JG, Duke SO. Investigating the mode of action of natural phytotoxins. J Chem Ecol. 2000;26:2079-2094. DOI: 10.1023/A:1005512331061.

32. Gaspar EMMSM, Neves HJC, Pereira MMA. Triterpenoids and other potentially active compounds from wheat straw: Isolation, identification, and synthesis. In: Cutler HG, Cutler SJ, editors. Biologically active natural products: agrochemicals. Boca Raton: CRC Press. 1999;69-80.

33. Gaspar EMMG, Pereira MM, Neves HJC. Potential allelopathic sterols and ketosteroids from wheat straw (Triticum aestivum). In: Macías FA, Galindo JCG, Molinillo JMG, Cutler HG, editors. Recent advances in allelopathy. Volume I. A Science for the future. Cádiz: Universidad de Cádiz. 1999;193-196.

34. Inderjit, Streibig JC, Olofsdotter M. Joint action of phenolic acid mixtures and its significance in allelopathy research. Physiol Plant. 2002;114:422-428. DOI: 10.1034/j.1399-3054.2002.1140312.x.

35. Blum U, Dalton BR, Rawlings JO. Effects of ferulic acid and some of its microbial metabolic products on radicle growth of cucumber. J Chem Ecol. 1984;10:1169-1191. DOI:10.1007/BF00988547.

36. Blum U, Dalton BR, Shann JR. Effects of ferulic and $p$-coumaric acids in nutrient culture of cucumber leaf expansion as influenced by pH. J Chem Ecol. 1985;11:15671582. DOI:10.1007/BF01012202.

(c) 2014 Dias; This is an Open Access article distributed under the terms of the Creative Commons Attribution License (http://creativecommons.org/licenses/by/3.0), which permits unrestricted use, distribution, and reproduction in any medium, provided the original work is properly cited. 